\title{
The Foundations of Hiroshi Motoyama's Integral Education
}

\author{
Thomas BROPHY \\ President, California Institute for Human Science, Encinitas, California, USA \\ thomas_brophy@cihs.edu
}

\begin{abstract}
Integral education is poised to become a unifying principle for global higher education that is suffering from fragmentation and disconnection from the essence of being human. Integral education does everything that conventional education does, and also categorically more by integrating multiple domains of learning and growth. Integral education can identify its roots with Integral Yoga and the integral philosophy developed contemporaneously by Sivananda and Aurobindo as a grand synthesis of all psychospiritual practices and theories, both Eastern and Western. These common roots can be traced in a direct line to two institutions founded specifically for integral education in the U.S.: the California Institute of Integral Studies (CIIS) founded by Haridas Chaudhuri and also to the California Institute for Human Science (CIHS) founded by Hiroshi Motoyama. Although the founders independently developed their philosophies of integral education, they identified their roots in the AurobindoSivananda Integral Yoga synthesis. Motoyama was a realized yogi as well as an educator and scientist. The educational and operational principles by which he founded cirs included the practice of methods for embodied psychospiritual growth. (All such methods are called "yogas" in the Vedanta tradition.) Although Motoyama developed his philosophy independently, his yoga roots mesh with those of Sri Aurobindo's Integral Yoga which is commonly thought of as the origin of integral education in the West. Moreover, Motoyama approved of Aurobindo's educational approach (Timothy Laporte, private communication).
\end{abstract}

\section{Keywords}

Hiroshi Motoyama - integral education - Sri Aurobindo - Ken Wilber - Saraswati Kazuo Inamori - Wang Yangming - ontology of ethics 
An extraordinary plenary presentation at the annual conference of the Western Association of Schools and Colleges highlighted the timeliness and applicability of this special issue. Organized around a theme of Provocative Questions, a panel discussion subtitled "Is Higher Education Accomplishing What it Said it Would" demonstrated an awakening awareness among higher education leaders of a need for connecting or reconnecting with integral education. The panel emphasized that, while external measures of success such as long-term salary, income and career advancement clearly demonstrate the value of a higher education, attempts by universities to assess precisely what has been learned by students during their education generally have not been able to identify any such measures. Panelists refreshingly and openly raised and discussed the questions: what is it that a higher education really is intended to impart, and what are the external voices relative to deep educational values and philosophies that are being heard by contemporary leaders in higher education? Panelists suggested that higher education is primarily not only about imparting data and knowledge, but that it could also be about developing what it is to be human in a society of humanity. The panel was notably unable to identify leading voices who are currently illuminating deep educational values and philosophies. All of this illustrates the openness, need, urgency, and relevance of integral education, as exemplified in the practice and theory of integral education advanced by Aurobindo, Sivananda, and Motoyama that I discuss in this paper.

\section{Ontological and Ethical Basis of Motoyama's Integral Education}

Hiroshi Motoyama founded the California Institute for Human Science (CIHS) in 1992. His self-directed integrative life path led to his founding of an integral university. A priestess in the shamanic Shinto religion, sought after by high levels of Japanese society, known as Odaisama, founder of the Tamamitsu Shinto religion, discovered Motoyama as a young boy. She identified him as her spiritual successor; and in a very unusual situation in Japanese society, she adopted the young Motoyama and raised him with his biological mother. Odaisama trained Motoyama in shamanic and yogic inner practices, while he simultaneously pursued conventional education in science and literature, achieving two doctoral degrees from prestigious universities. Motoyama continued his integrative development, practicing traditional methods of yoga, becoming a realized yogi while he advanced research in the scientific nature 
of spiritual development. He attracted eminent students and followers. To give one example of his far-reaching influence, the wealthy and distinguished industrialist and philanthropist Kazuo Inamori, who founded and endowed the Kyoto Prizes, was a student of Motoyama. Moreover, they co-authored a book, the Japanese title of which translates to Humanity's Search for Meaning.

Recently, Chinese scholars have noted striking similarities between the works of Inamori and Wang Yangming, a Ming Dynasty Neo-Confucian philosopher. For example, Zhuojun Lin (2017) compares Inamori's altruistic business philosophy and Wang Yangming's conscience-based strategic military philosophy. Both men introduced a higher mind intuition-based principle of action. In confronting an extreme complexity of business strategic action decisions, Inamori's philosophy poses the question: "As a person, what would be the right thing to do?" Wang Yangming described a developmental practice of mind learning, wherein accumulated bad habits of mind are wiped away to reconnect with an innately good conscience. In the view of those supporting integral education, Inamori and Wang Yangming can be seen as talking about the deeper levels of education, the education of the psychic and the spiritual dimensions of the human being.

Because wiping away accumulated detritus is a theme that runs through Wang Yangming's philosophy, his Philosophy of Mind has been called the Philosophy of Nothing (Lin, 2017). This is very similar to Motoyama's developmental consciousness philosophy of "absolutely Nothing". The fundamental underpinnings of Motoyama's approach to integral education can be found in his 2009 book, Being and the Logic of Interactive Function, in which he begins his preface with an ethical question:

In our contemporary period, among the enthused followers of religions in the world, we witness the terrorism that nonchalantly kills many people in the bid to gain power in the name of these religions - religions, which are instead supposed to save people. How has this come about, Iwonder? (p. xli)

Motoyama proceeded to explain this unethical and antisocial state of affairs as arising from a lack of experience of the ontologically fundamental one-body of all beings. He described this as an experience of union with the concept of the creative God as understood by the Abrahamic religions, that can be described with a simple metaphysical logic: ' $1+1_{2}+\ldots+1_{n}=1$,' where ' $n$ ' is the number of consciousnesses (i.e., spiritual beings) experienced as the same (physical) body. In other words, multiple spiritual consciousnesses are experienced as one physical body. 
Motoyama's metaphysics of ethics thus appears very similar to that of Wang Yangming as Bryan Van Norden describes in the The Stanford Encyclopedia of Philosophy:

Wang argues that the human mind is identical with the Pattern of the universe, and as such it forms "one body" (yi tĭ, one Substance) with "Heaven, Earth, and the myriad creatures" of the world. The difference between the virtuous and the vicious is that the former recognize that their minds form one body with everything else, while the latter, "because of the space between their own physical form and those of others, regard themselves as separate" (2020, p. 241).

Motoyama identified the experience of union with the creative God in the case where the number of beings, 'n,' extends to all sentient beings as, "the divine consciousness which Christ and Mohammed achieved" (2009, p. xlix), and therefore a principle of identity that is adhered to by "the Semitic religions such as Judaism, Christianity, and Islam" (2009, p. xlix).

In Being and the Logic of Interactive Function, Motoyama continued his development of metaphysical logic, informed by his own experiences in yogic meditation, in an effort to integrate Eastern and Western religions; and he also integrates them with "the truth of physical science" (p. xlix). He describes a hierarchical sequence of categories of religious union experiences in which divine union with the creative God is the highest form of experience that can be explained with Aristotelian logic. He correlates the hierarchical development of religious experiences with hierarchies articulated by Eastern and Western sages including Patanjali, St. Teresa, St. John of the Cross, and Kukai. In Motoyama's hierarchy, the stage of union with the creative God is still relative to a deeper or higher ground out of which the creation arises. He called this deeper/higher ground, "absolutely Nothing".

This is the level at which Motoyama's metaphysical ontology integrates with modern physical science. Aristotelian logic is based on common-sense fundamental postulates: the principle of identity, 'A = A,' and the principle of the excluded middle, ' $\mathrm{A} \neq$ not $\mathrm{A}$.' Motoyama said progression through the stages of religious unity experiences involves a negation or voiding of identity with each previous stage. He extended the sequence of stages to beyond the stage of union with the creative God. This results in a metaphysical symbolic logic equation " $1+1_{2}+\ldots+1_{n}=0$.". This "absolutely Nothing" violates Aristotelian logic because ' $\mathrm{A}=\mathrm{A}$ ' and ' $\mathrm{A}=$ not $\mathrm{A}$ '; it is a "logic of not". By his identifying this highest, and trans-logical stage of religious unity experience in this way and with hierarchical religious stages articulated by multiple experiencers, 
Motoyama unifies global religious expression East and West. Moreover, he opens the door to integration with modern science.

In the translator's introduction to Being and the Logic of Interactive Function, Shigenori Nagatomo bolsters Motoyama's argument that versions of his metaphysical 'logic of not' exist in the Mahayana Buddhist concept of emptiness (sunyata) and in the Daoist concept of the Dao (Zhuangzi's chaos, indeterminate, formless). It involves "the rejection of the belief that there exist things corresponding to our linguistic activity that postulates the existence of substance or essence (2009, p. xxxvii)". Importantly, Motoyama notes the similarity of this to the underpinnings of modern physics. The significance is that the logic of Motoyama's metaphysical ontology is strikingly similar to that of the Copenhagen Interpretation of quantum physics. In fact, they are essentially identical. Whereas Motoyama arrived at this metaphysical logic of being through his attempts to reconcile his direct experience in meditation with the great religious texts of the East and West, the Copenhagen Interpretation of physics is arrived at through attempts to reconcile empirical outcomes of physics experiments. This unified ontological view including a scientific basis informs Motoyama's approach to integral education. In this view, integral education necessarily includes education of the multiple levels of being beyond that of the cognitive intellect, and it seeks its validation through expanded scientific methodologies that acknowledge the existence of multiple levels of being.

\section{Independently Developed Integral Education Connected with} Other Traditions

Motoyama included in his approach the Integral Yoga tradition of Swami Sivananda Saraswati. Sivananda, who was an Indian compatriot and contemporary of Aurobindo, was the primary modern developer and pioneer of Integral Yoga. In Motoyama's seminal work Theories of the Chakras: Bridge to Higher Consciousness (1981), Motoyama compared the human chakras system as directly perceived by three practitioners of kundalini yoga chakra awakening: Theosophist C. W. Leadbeater, Sivananda's disciple Swami Satyananda, and Motoyama himself.

In his Foreword to Motoyama's Theories of the Chakras, Satyananda described the authenticity of Motoyama's methods and experiences:

This present book - is an outstanding document from both the scientific and spiritual points of view. In the first place, it presents a unique and 
authentic record of the spiritual experiences of an adept in whom the kundalini has been awakened by yogic practices. And second, it is the unique record of the pioneering experiments conducted at the Institute for Religious Psychology, Tokyo... (1981, p. 7).

Satyananda noted his support of Motoyama's project to bridge science and spirit, stating, "Today kundalini is being discussed in every society, language, and country in the world. Young scientists especially should dedicate themselves to recognizing and understanding [it's] effects" (1981, p.xx) Subsequent to their collaboration related to the Theories of the Chakras, Motoyama discouraged involvement in Satyananda's ashram out of his concern regarding Satyananda's conduct as a teacher; however, he maintained contact with the foundational Integral Yoga tradition of Sivananda.

Sivananda, a prominent Indian national leader, spiritual teacher and Vedantist whose image appeared on an Indian national postage stamp in 1986, led the modern development of Integral Yoga. Calling his yoga the Yoga of Synthesis, Sivananda integrated the primary paths and sub-paths of yoga and the Yoga Sutras of Patanjali. As described on Sivananda's Divine Life Society website (www.sivanandaonline.org):

The four main spiritual paths for God-realization are Karma Yoga, Bhakti Yoga, Raja Yoga and Jnana Yoga. Karma Yoga is suitable for a man of active temperament; Bhakti Yoga for a man of devotional temperament; Raja Yoga for a man of mystic temperament; Jnana Yoga for a man of rational and philosophical temperament or enquiry. The practice of Yoga leads to communion with the Lord. Whatever may be the starting point, the end reached is the same.

Raja Yoga, for example, is sometimes described as a combination of Laya Yoga, a yoga of energies of the body such as prana and kundalini energy, and Hatha Yoga, a yoga of physical postures. It is common in popular Western thinking to equate yoga only with the physical postures of Hatha. Bhakti Yoga can be thought of as the yoga of devotion to God or gods and goddesses. Karma Yoga is the yoga of good works and thoughts in the world. Jnana yoga can be thought of in simple terms as a yoga of the mind and knowledge (see Skananda, 1955). The multiple paths of yoga included in the Yoga of Synthesis can be seen as yogic practices for the multiple levels of being in Motoyama's ontological view, and Motoyama included them in his teaching of contemplative practices. As such, this is also a basis for integral education at CIHS. 
Sivananda's disciple Satchidananda Saraswati called his version of the Yoga of Synthesis, Integral Yoga, and opened Integral Yoga centers around the globe that attracted many notable Western followers. Artist Peter Max brought Satchidananda to America, and Satchidananda appeared in meditation on stage as the opening act of the Woodstock Festival in 1969.

Swami Sivananda established The Divine Life Society in 1936. Sri Aurobindo, who was 15 years older than Sivananda, published his major work The Life Divine in 1944. As we can see, Aurobindo and Sivananda were the key figures in the modern development of Integral Yoga, with Aurobindo creating integral philosophy and developmental integral psychology; and Sivananda developing Integral Yoga and spreading it throughout the world via several prominent disciples, fifteen of whom founded new organizations for the advancement of Integral Yoga. In an integrative series of essays (www.sivanandaonline.org) on "Saints of Modern Times", Sivananda wrote of Aurobindo's philosophy:

Sri Aurobindo's philosophy is in a sense practical. It is based on facts, experience and personal realizations and on having the vision of a seer or Rishi. Aurobindo's spirituality is inseparably united with reason.

The goal aimed at by Sri Aurobindo is not merely the liberation of the individual from the chain that fetters him, but "to work out the will of the Divine in the world, to effect a spiritual transformation and to bring down the divine nature and a divine life into the mental, vital and physical nature and life of humanity.

A fixed and unfailing aspiration that calls from below and a Supreme Grace that answers from above are two powers which in their conjunction can effect this. If the transformation is to be integral, integral should be the rejection of all that withstands it". says the Master Sri Aurobindo.

Aurobindo's Life Divine is, and will always remain, a force guiding the thoughts of men all over the world (www.sivanandaonline.org).

Sivananda ended his essay on Aurobindo with a statement about his role in a coming grand synthesis of Eastern and Western wisdom traditions:

The crest jewel of renascent India, the bravest among the patriots, the sharpest among the intellectuals, and the subtlest among the seers, Sri Aurobindo fulfilled the glorious purpose of demonstrating to the world that real India, the India of the Vedic seers, could survive and absorb into herself all alien cultures, and that at the hands of one who knew the proper synthesis, Eastern and Western cultures could find their happy blend, without necessarily having to antagonize one another. 


\section{Integral Education Comes to America}

Near the end of his life, Aurobindo recommended his student and eminent scholar of his work, Haridas Chaudhuri, to the founder of the American Academy of Asian Studies in San Francisco. Chaudhuri became one of its founding professors together with Buddhist scholar Alan Watts (author of The Way of Zen 1957). As Joseph L. Subbiondo, president emeritus of CIIS, points out (2017) this founding of the first graduate school devoted exclusively to the study of Asia can be seen as the origin of integral education in the United States. Chaudhuri founded the Cultural Integration Fellowship devoted to an understanding of East and West which sponsored the founding of CIIs in 1968. Chaudhuri adapted Aurobindo's approach to integral education to higher education and shaped the institutional mission of cIIs (see Chaudhuri 1965).

Ken Wilber is among the most prominent proponents of integral studies and integral theory in the West. Wilber left a biochemistry doctoral program at Duke University and traditional American higher education to pursue full time research into the nature of consciousness. He applied methodological pluralism in an effort to integrate essentially all world-wide theories of consciousness development, especially the gradations and stages of consciousness. This grew into the development of an integral psychology and then a full-blown integral paradigm (see Wilber 1995). Wilber was significantly influenced by the integral philosophy of Aurobindo, whom he considered perhaps India's greatest modern philosopher-sage. Wilber was influenced by Chaudhuri and cIIs through friends of CIIs, Francis Vaughn and Roger Walsh, along with his first wife Terry Killam who was a ciIs student (Subbiondo 2017).

Wilber is also influenced by ciHs founder Motoyama, citing Theories of the Chakras as Wilber's primary reference on the "subtle body" systems. By applying his methodological pluralism, Wilber's extensively annotated and referenced works (e.g. 1995, 2000), and he cross-referenced integral philosophy and integral theory with ancient and modern scholarly sources, Eastern and Western, especially classical Greek Platonists, Neo Platonists, esoteric Buddhists, Christian saints, as well as modern and postmodern integrative and developmental sources. Out of his involvement with Naropa Institute, the first accredited Buddhist university in the U.S., Wilber founded the Integral Institute to apply integral studies in multiple fields from business and leadership to medicine, psychology, politics, art, and integral education.

A distinction can be drawn between Wilber's work and those of Aurobindo and Motoyama who functioned in roles of gurus of the practice of Integral Yoga, as well as scholars of those methods and traditions. Wilber, on the other hand, 
is a pluralistic and integrative analytical scholar of methods and meta-theories without taking up the mantle of guru of a lineage of practice. Integral psychology, integral philosophy, integral studies, integral theory all have their roots in Integral Yoga. In addition, they inform the development of integral education theory and practice.

\section{5 \\ Integral Education Pedagogy}

Motoyama's and Aurobindo's common Integral Yoga philosophy roots are seen in commonalities of their views on integral education. Something beyond the simple transfer of knowledge is central to integral education. In an essay $\mathrm{On}$ Education (1956), together with Mira Alfassa, Aurobindo maintained the "central aim is the building of the powers of the human mind and spirit, it is the formation or ... [as he would prefer] the evoking of knowledge and will and of the power to use knowledge, character, culture - that at least if no more" (pp. $9^{-10)}$. And this "something more" than knowledge transfer includes the possibility of developing what Aurobindo called Supermind, and what Motoyama identified as Superconsciousness.

Motoyama developed his understanding of superconsciousness similarly as Sivananda said Aurobindo developed his understanding of supermind, "based on facts, experience and personal realizations and on having the vision of a seer or Rishi" (1981, p. $x x$ ) This psychospiritual development, arrived at through holarchically enveloped stages of yogic practice, is simultaneously nondual and very complex: an embodied trans-complexity. Stages of yogic practice are accompanied by increasingly complex capacity for perspective taking, from the commonly understood first person, second person, and third person perspectives, to what they considered fourth person and fifth person perspective capacities. Buddhist mandala-visualization meditation practice mirrors such development, as the practitioner visualizes increasingly complex mandalas until there is a consciousness transformation to unitive awareness.

Chapter One of Motoyama's Being and the Logic of Interactive Function, "Religious Experience and Being", first published in Motoyama's doctoral dissertation (1962) for Tokyo University, describes a hierarchical sequence of stages of mystical experience very similar to stages later described by Wilber. Motoyama also correlated with some of the same key experiencers as does Wilber (namely, Patanjali, St. Teresa, St. John of the Cross, and Kukai). Given that Wilber's first book The Spectrum of Consciousness was published in 1977, clearly Motoyama's integral education constructions were independent of Wilber's. In that they are similar in evidence, point to similar integral realities, 
and were independently discovered, suggests they also point to the same ontic reality.

At CIHS, integral education pedagogy accepts the existence and value of trans-disciplinarity, multiple ways of knowing and is inclusive of multiple academic disciplines, and something more than a mere connection of knowledge-based disciplines. While trans-disciplinarity involves multiple domains, it is transrational in the domain of reason fully inclusive of the rational stage; and it involves something more that has capacity to operate on the domain of reason as a whole.

As can be seen generally in the writings of Aurobindo, Motoyama, and Wilber, in contrast to conventional worldviews that privilege only empirical knowledge, integral philosophy generally includes the relevance of interior/ spirit/consciousness aspect of being that is not reducible to or emergent from exterior and material aspect; and the fundamental existence of sociality and collective aspect of being that is more than merely a collection of individuals. For example, at CIHS in a course entitled Foundations in Integral Studies, students practice and report on their experience of an "integral life practice" that involves brief practices that exercise and develop each of the five "bodies" that, Motoyama and integral theory claim constitute the human being.

Zulaski (2017) succinctly views integral education as elucidated by Sri Aurobindo and Mira Alfassa, as education of the same five "bodies" as Motoyama and Wilber contend.

- Education of the physical body. This is essential, not only recreational, and can include somatic, kinesthetic, expressive arts, martial arts, athletics, dance, and Hatha yoga.

- Education of the vital body, referred to as astral body, prana, chi, acupuncture meridians and various other names. Zulaski notes, "The Mother [Mira Alfassa] defines one's 'vital being' as the 'set of impulses and desires, of enthusiasm and violence, of dynamic energy and desperate depression, of passions and revolts"' (p. 23). Motoyama developed a type of vital education combined with physical kinesthetic education that he called "meridian exercises".

- Education of the mental body. This includes traditional cognitive development, and beyond. Zulaski lists, "attaining knowledge, memory, progression from object-based to abstract-concept relations, gestalt, contemplation, inspiration, intuition, and imagination" (p 24). Integral accepts the existence of higher stages of cognitive development, beyond formal operational reason. Wilber (2000, p. 202) identifies these postformal stages of cognitive development as articulated by Aurobindo and correlates them with other systems, with the first postformal level Wilber calls "vision-logic", others 
call transcendental-thinking, Aurobindo labeled illumined mind. (And Aurobindo identifies two more stages leading to supermind.) Motoyama (1981, 1990, 2009) also discussed higher cognitive developmental stages and the importance of education of the mind. Conventional education has come to value only this aspect, education of the mind, and has collapsed it to only the contents and methods up through formal operational reason.

- Education of the psychic body. Zulaski quotes Alfassa "'with psychic education we come to the problem of the true motive of life, the reason of our existence on earth...the consecration of the individual to his eternal principle"' (p. 25), and further, "it is through the psychic presence that the truth of an individual being comes into contact with him and the circumstances of his life"' (p. 25). In metaphysical systems that recognize holarchically nested sheaths of body-being from physical to vital (astral), this level of body is called "causal" in Theosophy, and Motoyama uses the original Sanskrit karana body. Motoyama writes (1990:72), "when a practitioner enters the world of karana, all this [sensory realm] becomes transparent, and those experiences which belong to the astral dimension - the feelings, emotions and desires - no longer interfere with experience that now consists primarily of intellect and knowledge".

- Education of the spiritual body. This aspect is considered of utmost importance; the highest object of education. Zulaski quotes Alfassa, "the manifestation of Truth...[to] make matter ready to manifest the Spirit"' (p. 26). Similarly, Motoyama states in his principles of education, "to actualize mental control over body and matter with a resulting better life" (www.cihs.edu). CIHS stives to educate and assess "well-being" of all five bodies, across all systems of operations including student-learning, faculty-teaching, and administration-oversight. On this view, the essential difference between integral education and conventional education is the latter has collapsed to only education of the mental body (cognitive development), while integral education includes attention to all five aspects. Importantly, however, this is a difference of inclusion not dissociation. Integral education includes conventional education, and much more.

Informed by the metaphysical ontology articulated in Being, Motoyama established eight principles to guide the mission and operation of CIHS as an integral education institute. Two principles especially show commonality with Aurobindo's and Alfassa's discussions of integral education theory: to establish a creative science in which one can research the mind and soul as well as matter; and to establish a society which satisfies both the individuality (freedom and rights) and sociality (morality and coexistence) of human existence. 
Motoyama and integral education methods generally employ multiple ways of knowing and being: logic-reason application, mindfulness, somatic awareness methods, intuition, the multiple categories of yogas, and siddhis any method of apprehension that is amenable to intersubjective validation. Motoyama's approach to integral education thus aligns with Integral Drama Based Pedagogy (ID BP). ID вP focuses on the integration of body-mind-spirit, and has four parts: mindfulness and meditation, dramatic play, drama process, and sharing and discussion. Mindfulness and meditation make the participants quiet and at peace, with high concentration and sensitivity throughout the whole body.

The great practitioner of Jnana Yoga and patriot-saint of modern India, Vivekananda, wrote of the difference between knowledge transfer and "realization":

Talking is one thing and realizing is another. Philosophies and doctrines and arguments and books and theories and churches and sects and all such things are good as far as they go; but when realization comes these things drop away. For instance, maps are good, but when you see the country itself and look again at the maps, what a great difference you find! (1955, p. 203)

Importantly, while the multiple methods of apprehension involve domains beyond that of reason, the domain of reason is never diminished or denigrated. As Sivananda wrote of Aurobindo, “Aurobindo's spirituality is inseparably united with reason" (1981, p. xxx).

Particularly relevant to Motoyama's foundations of integral education as practiced at CIHS are the following:

- Inclusion of scientific research into the functioning of all the five bodies, including the nonphysical subtle bodies, qi energies, or chakra-nadi energies, effecting human physiology,

- Study and practice of psychophysical exercises designed to develop the subtle bodies as well as the physical body. Examples include a "Meridian Exercises" system developed by Motoyama, Yin Yoga, and kundalini yoga practices as described by Motoyama (1981),

- Inclusion of studies and research that seek to integrate global religions, rather than only compare them,

- Inclusion of studies and research that seeks to integrate physical sciences with metaphysical ontologies.

Motoyama-based education pedagogy, and Integral Drama Based Pedagogy, arise from and are part of a polycentric and continually evolving set of coherent 
traditions with common elements. These integral pedagogies are poised to be a unifying force for global higher education systems that seek to heal from the fragmentation and disconnection from the essence of human being and human progress, that they are suffering.

\section{Challenge for Integral Education}

A challenge for integral educators was indicated by Devdip Ganguli, professor at Sri Aurobindo International College (SAIC) in Pondicherry, at the Gnostic Centre International Conference on Integral Education (February, 2019, Delhi, India). Ganguli spoke of the principle of integration for integral education. He noted that the principle which ties all parts of our being, and leads them, organizes them, and makes them a vessel which is a whole. And that principle of integration is the 'Psychic Being'. As to the methods used to bring forth the Psychic Being, Ganguli continued, noting that we understand it in the sense of creating an atmosphere where those who are seeking it and who have some readiness for it, may find it. And this creation of the atmosphere is essentially a factor of many different factors: there are the teacher, the environment, and a presence or a guide.

Two of Motoyama's eight principles speak to a principle of integration similar that of Aurobindo's evoking Psychic Being: to elucidate the mechanism of the correlation between mind and body, and to actualize mental control over body and matter with a resulting better life, and to systematize scientific and objective meditational practices that promote spiritual growth. These principles speak to the integration of religion, science, and global sustainability: to promote a society which enhances the integration of science and religion; and to establish guiding principles for the citizens of the global society.

The challenge is finding and improving methods to address the deeper aspects of education that may occur only rarely, and in non-systematic ways. Zen Buddhist practitioners speak of "dharma transmission" which is a transmission of knowledge-love-wisdom from Zen master to Zen student that occurs when the body-mind-spirit systems of student and teacher are properly tuned. Dharma transmission can thus be seen as a type of method for the deeper aspects of integral education, the education of the psychi and the spirit. But given that dharma transmission happens without any schedule or system, only after years of meditation; and not for many or most practitioners, it would not be suitable as a standard method for higher education. But Zen practice would be suitable, as it "creates an atmosphere", as Ganguli said, conducive to psychic education events. Similarly, philosopher J. Krishnamurti 
spoke of the importance of "action without ideation", and freedom from the known (1969). Krishnamurti founded several schools that could be thought of as incorporating integral education aspects along these lines, with educational objectives: global outlook; concern for human and the environment, and support of religious spirit.

The integral education stance toward religion is inclusive and integrative, from inter-religious to trans-religious. Integral education is conversant with all wisdom traditions. For example, Sivananda describes a prophet or religious teacher in The Divine Life Society:

Hinduism, Zoroastrianism, Judaism, Buddhism, Christianity and Islam are the six great religions of the world. There is no founder for Hinduism. All the other religions have their founders. They are named after the name of the founder (except Islam). Jainism is only another form of Buddhism. Sikhism is based chiefly on Hinduism and partly on Islam. Brahmoism is born of Hinduism and Christianity and so on with other minor religions.

Whenever any important truth of religion was suppressed by the arrogance and selfishness of the priestly class or forgotten through the ignorance of the people, there appeared a great Saint or Prophet or Religious Teacher. He emphasized that truth, removed the dross which had concealed or obscured it and made it shine in its original brilliance, purity, splendour and glory (www.sivanandaonline.org)

Similarly, an integral approach looks to the saints and sages of all wisdom traditions, East and West, ancient and modern.

Some approaches to integral education could be regarded as "soft" in that, while trying to include holistic and transpersonal ways of knowing beyond the cognitive way, they devalue the critical thinking faculties of the mind. Motoyama and CIHS' approach to meeting the challenges of integral education emphasizes reconnecting with a broadened scientific method and global systems approach that embrace and heighten the critical thinking faculties of the mind.

\section{Acknowledgements}

I thank Joseph Subbiondo for his generous reviews and commentary during the development of this paper. I am grateful to Liwen Ma for her visionary leadership in the area of integral education and drama based pedagogy, and insightful comments on a preliminary draft. Timothy Laporte supplied invaluable 
comments and perspective, and Richard Jelusich provided appreciated input. Sean Esbjörn-Hargens gave insightful key comments. Much gratitude to Ameeta Mehra for generously hosting the conference on Integral education, and for her founding and shepherding of the Gnostic Center in Delhi. I thank Devdip Ganguli for discussions during the conference on Integral education. Especially, I am grateful to Tamamitsu Jinja for its ongoing generous support of the advancement of CiHS and its long-standing commitment to the integral thories and practices of Hiroshi Motoyama.

\section{References}

Aurobindo, S. (1944) The Life Divine. Twin Lakes, Wisconsin: Lotus Press.

Aurobindo, S., \& Alfassa, M. (1956) On Education. Pondicherry, India: Sri Aurobindo Ashram Press.

Chaudhuri, H. (1965) Integral Yoga: A Concept of Harmonious and Creative Living. Wheaton, Illinois: Theosophical Publishing House.

Ganguli, D. (2019) Contemplative dialogues \& practices in integral higher education. Transcript.

Krishnamurti, J. (1969) Freedom from the Known. San Francisco: HarperCollins.

Lin, Zhuojun. (2017) Wang Yangming's Mind Theory and Inamori Kazuo's Mind Management Philosophy. (translated) Enterprise Reform and Management.16: 149 DOI:10.13768/j.cnki.cn11-3793/f.2017.3248.

Motoyama, H. (1981) Theories of the Chakras: Bridge to Higher Consciousness. Wheaton, Illinois: The Theosophical Publishing House.

Motoyama, H. (1990) Toward a Superconsciousness: Meditational Theory and Practice. Berkeley, CA.: Asian Humanities Press.

Motoyama, H. (2009) Being and the Logic of Interactive Function. Tokyo: Human Science Press.

Subbiondo, J. (2017) The evolution, adaption, and application of an integral model of education: Sri Aurobindo, Haridas Chaudhuri, and Ken Wilber. The Awakening Ray 21:5-14.

Sivananda, Saraswati. http://www.sivanandaonline.org.

VanNorden, B. (2020) Wang Yangming. In Edward N. Zalta (Ed.) The Stanford Encyclopedia of Philosophy, Stanford, CA: Stanford University Press. Retrieved from: https://plato.stanford.edu/archives/spr2o2o/entries/wang-yangming/>.

Vivekananda, S. (1955) Jnana-Yoga. New York: Ramakrishna-Vivekananda Center. Watts, A. (1957) The Way of Zen. New York: Pantheon Books.

Wilber, K. (1995) Sex, Ecology, Spirituality: The Spirit of Evolution, Boulder, CO: Shambhala. 
Wilber, K. (2000) Integral Psychology: Consciousness, Spirit, Psychology, Therapy. Boulder, CO: Shambhala.

Zulaski, J. (2017) A complete integral education: five principal aspects. Integral Review, $13(1), 20-29$. 